\title{
TIPOS DE ESTACAS, DOSES DE ÁCIDO INDOLBUTÍRICO E MÉTODOS DE ENXERTIA PARA PROPAGAÇÃO DE TAPEREBÁ
}

Dheimy da Silva Novelli', Sebastião Elviro de Araújo Neto ${ }^{2}$, Luís Gustavo de Souza $\mathrm{e} \mathrm{Souza}^{3}$, Nilciléia Mendes da Silva ${ }^{4}$, Regina Lúcia Félix Ferreira ${ }^{5}$

${ }^{1}$ Engenheira Agrônoma, Doutorado em Produção Vegetal. Professora do Instituto Federal de Rondônia, Cacoal, RO.

${ }^{2}$ Engenheiro Agrônomo, Doutorado em Fitotecnia. Professor da Universidade Federal do Acre, Rio Branco, AC.

${ }^{3}$ Engenheiro Agrônomo, Universidade Federal do Acre, Rio Branco, AC. E-mail: gustavo_souza_fj@hotmail.com

${ }^{4}$ Engenheira Agrônoma, Universidade Federal do Acre, Rio Branco, AC.

${ }^{5}$ Engenheira Agrônoma, Doutorado em Fitotecnia. Professora da Universidade Federal do Acre, Rio Branco, AC.

\section{Recebido em: 02/10/2017 - Aprovado em: 21/11/2017 - Publicado em: 05/12/2017} DOI: 10.18677/EnciBio_2017B63

\begin{abstract}
RESUMO
As frutíferas amazônicas popularmente conhecidas como taperebá (Spondias macrocarpa Engl.) possui frutos com sabor agridoce de ótima aceitação em mercados locais, entretanto, não possui ainda pomares comerciais. O objetivo deste trabalho foi avaliar métodos de enxertia e doses de ácido indolbutírico na propagação vegetativa de taperebá. Os experimentos foram implantados em casa de vegetação, com nebulização intermitente, em delineamento inteiramente casualizado. Estacas apicais, medianas, basais, basais estratificadas e tanchão foram tratadas com 0, 1.000, 2.000, 3.000, 4.000 e $5.000 \mathrm{mg} . \mathrm{L}^{-1}$ de ácido indolbutírico. Foi avaliado enxertia pelos métodos de janela aberta, janela fechada, garfagem em fenda cheia, garfagem em fenda dupla e garfagem lateral. Foram avaliadas, na estaquia, a percentagem de estacas vivas, brotadas, com calos, com raiz, o número de raízes e brotos, o comprimento da maior raiz e a massa seca de raízes e brotos aos 120 dias após a estaquia; e nas enxertias avaliou-se a percentagem de pegamento e a sobrevivência dos enxertos aos 30 e 60 dias, respectivamente, após a enxertia. As análises estatísticas foram feitas pelo teste não paramétrico de Kruskal-Wallis. As doses de AIB 0, 2.000, 3.000 e 5.000 mg. L-1 aumentaram a percentagem de estacas vivas. As doses de AIB e os tipos de estaca não afetam o enraizamento. A enxertia por garfagem lateral proporciona maiores taxas de brotação do enxerto, que é baixo (25\%) para esta espécie.
\end{abstract}

PALAVRAS-CHAVE: Estaquia, Propagação assexuada, Spondias macrocarpa Engl., 


\title{
TYPE OF CUTTING, DOSES OF INDOLEBUTYRIC ACID AND GRAFTING METHODS FOR PROPAGATION OF TAPEREBA
}

\begin{abstract}
The Amazonian fruits popularly known as tapereba (Spondias macrocarpa Engl.) have sweet-sourced fruit of great acceptance in local markets, however, neither commercial orchards. The objective of this work was to evaluate the methods grafting and indolebutyric acid doses in the propagation of the taperebá. The experiments were done in a greenhouse, with intermittent misting, in a completely randomized design. Apical, medial, basal, stratified basal and tanchan cuts were treated with 0 , $1,000,2,000,3,000,4,000$ and $5,000 \mathrm{mg} \mathrm{L}^{-1}$ of indolebutyric acid. Grafting was assessed by open patch budding, closed patch budding, full cleft, double cleft and single cleft methods. The percentage of live cuttings, buds, calli with root, number of roots and shoots, root length and dry mass of roots and shoots at 120 days after cutting were evaluated in cuttings; And in the grafts the percentage of glue and the survival of the grafts were evaluated at 30 and 60 days, respectively, after the grafting. Statistical analyzes were performed by Kruskal-Wallis non-parametric test. Doses of AIB $0,2,000,3,000$ and $5,000 \mathrm{mg} . \mathrm{L}^{-1}$ increased the percentage of live cuttings. AIB rates and stake types do not affect rooting. Grafting by lateral grafting provides higher rates of graft budding, which is low (25\%) for this species.
\end{abstract}

KEYWORDS: Spondias macrocarpa Engl., Asexual propagation, Rooting.

\section{INTRODUÇÃO}

O gênero Spondias pertence à família Anacardiaceae, possui algumas espécies frutíferas de boa aceitação pelos consumidores. Na região Norte do Brasil, o cajá (Spondias mombin L.) e o taperebá (Spondia macrocarpa Engl.) e na região Nordeste outras espécies do gênero como o umbu ( $S$. tuberosa Arr.), cajá-manga ( $S$. cytherea Sonn.), umbu-cajá (Spondias sp.), umbuguela (Spondias sp.) e a ciriguela (S. purpurea L.), são muito consumidas na alimentação humana (LIMA FILHO et al., 2009; BASTOS et al., 2014).

Domesticar mais espécies frutíferas é essencial para a fruticultura comercial pois o aumento da diversificação das espécies diminui os riscos com os efeitos cíclicos do mercado e do ambiente e fornece renda prolongada pelas diferentes sazonalidades das espécies, contribuindo para o desenvolvimento regional.

O taperebá, também conhecido como cajá-redondo (Spondia macrocarpa Engl.) são frutos globosos ou ovoides, tipo drupa, com polpa suculenta e fibrosa, de sabor ácido, utilizadas principalmente para fabricação de polpa, sucos, néctares e sorvetes, não é ainda cultivada comercialmente (LORENZI et al., 2006).

A propagação por sementes das plantas do gênero Spondias quando possível torna-se um problema para o estabelecimento de plantios comerciais pelo longo período juvenil que atrasa a produção, sendo a propagação vegetativa uma alternativa para exploração comercial das espécies deste gênero (DUTRA et al., 2012).

A seleção de características agronômicas em frutíferas é facilmente alcançada pela clonagem (FACHINELLO et al., 2013), sendo comum sua utilização na propagação de inúmeras frutíferas e sendo também necessária em Spondias para a implantação de pomares comerciais (DUTRA et al., 2012; HOLANDA et al., 2012; RIOS et al., 2012; BASTOS et al., 2014). 
O enraizamento adventício de estacas das espécies do gênero Spondias é baixo (HOLANDA et al., 2012; RIOS et al., 2012; BASTOS et al., 2014), mesmo utilizando hormônios sintéticos de enraizamento como ácido indolbutírico (AIB) que na Spondias lutea, o enraizando é de apenas 1,3\% e 2,7\% com doses de 2.500 a $5.000 \mathrm{mg} \mathrm{L}^{-1}$, respectivamente (HOLANDA et al., 2012). Porém, a aplicação de doses crescentes de AIB pode elevar a percentagem e o número de raízes, como ocorre com o umbuzeiro, de $11,2 \%$ sem AIB até $30,5 \%$ na dose de $6.000 \mathrm{mg} \mathrm{L}^{-1}$ de (RIOS et al., 2012).

A utilização de técnicas de enxertia também se constitui em alternativa de propagação vegetativa das espécies do gênero Spondias, sendo preferíveis os métodos de garfagem (BASTOS et al., 2014), predominantemente garfagem em fenda cheia (LIMA FILHO; SANTOS, 2009) como eficiente para a maioria das espécies frutíferas propagadas por este método (GÓES et al., 2016).

O gênero Spondias também pode necessitar de porta-enxerto adaptado ao ambiente, seja pela resistência a doenças, tolerância a estresse hídrico ou precocidade de produção (LIMA FILHO; SANTOS, 2009; SOUZA et al., 2012; WARSCHEFSKY et al., 2016). Lima Filho e Santos (2009) avaliando o umbuzeiro como porta enxerto, observaram diferentes percentagens de pegamento do enxerto de cajá-manga $(25 \%)$, cajá $(66,7 \%)$, ceriguela $(85,7 \%)$, umbu-cajá $(88,9 \%)$ e umbuguela $(100 \%)$, com início de produção após o transplantio de dois anos para ceriguela e cajá-manga e cinco anos para as demais espécies. Em cajazeira, o porta-enxerto e a enxertia não alteram o padrão de crescimento dos clones, sem indícios de incompatibilidade.

Portanto, o objetivo deste trabalho foi avaliar métodos de enxertia e doses de ácido indolbutírico na propagação vegetativa de taperebá.

\section{MATERIAL E MÉTODOS}

Foram instalados quatro experimentos no Sítio Ecológico Seridó, município de Rio Branco - AC, latitude de 9 53' 16" S e longitude de 67 49' 11" W, altitude de 170 m. O clima é característico da região amazônica com temperatura média anual de $24,5^{\circ} \mathrm{C}$, com máxima de $32^{\circ} \mathrm{C}$, altos índices pluviométricos que variam de 1.600 $\mathrm{mm}$ a $2.750 \mathrm{~mm}$ anuais, com duas estações sendo estas, seca e chuvosa (ACRE, 2010).

Os experimentos foram realizados em casa de vegetação coberta com filme aditivado e $100 \mu$ de espessura e sob este, tela de sombreamento com $50 \%$ atenuação da radiação, sendo as laterais protegidas por tela antiafídica. A irrigação utilizada foi por nebulização intermitente, controlada por timer regulado para irrigar 2 minutos com intervalos de 40 minutos, com objetivo de manter a umidade relativa do ambiente elevada e reduzir a temperatura. A umidade relativa e a temperatura foram acompanhadas com um termohigrômetro digital, registrando temperatura média de $26,4 \stackrel{\circ}{\circ}$ e umidade relativa do ar média de $72,2 \%$.

O experimento de estaquia foi instalado no final de julho de 2015 com estacas coletadas de plantas em estado vegetativo. Foram coletadas estacas do tipo tanchão (60 cm de comprimento e diâmetro médio de $39,38 \mathrm{~mm} \pm 13,10 \mathrm{~mm}$ ) basais e basais estratificadas $(20 \mathrm{~cm}$ de comprimento e diâmetro médio de $11,47 \mathrm{~mm} \pm$ $1,42 \mathrm{~mm}$ ), medianas (15 cm e diâmetro médio $8,09 \mathrm{~mm} \pm 1,29 \mathrm{~mm}$ ) e apicais $(12 \mathrm{~cm}$ e diâmetro médio $6,63 \mathrm{~mm} \pm 0,75 \mathrm{~mm}$ ).

Para cada tipo de estaca foram testadas as doses de ácido indolbutírico (AIB): $0,1.000,2.000,3.000,4.000$ e $5.000 \mathrm{mg}^{-1} \mathrm{~L}^{-1}$ da auxina em talco inerte. As estacas estratificadas foram tratadas com AIB, depositadas no viveiro e cobertas com 
palhada de material vegetal umedecido, onde permaneceram por 30 dias e só então foram colocadas nos tubetes com vermiculita, assim como as demais estacas. $O$ delineamento experimental foi inteiramente casualizado, em fatorial $5 \times 6$ com 4 repetições com 10 estacas por repetição.

Após 120 dias foram avaliadas: a percentagem de estacas vivas, com brotos, com calos e enraizadas, o número de raízes e a massa seca das raízes (MSR) e a massa seca dos brotos (MSB). Para as avaliações de massa seca, as raízes e os brotos foram retirados das estacas com auxílio de tesoura de poda e acondicionados em sacos de papel identificados, levados a estufa com temperatura de $70{ }^{\circ} \mathrm{C}$, mantidos até atingirem massa constante aferida em balança de precisão.

O experimento de enxertia foi instalado em outubro de 2015. Utilizou-se a espécie taperebá, tanto para porta-enxerto quanto para copa. As sementes foram coletadas e semeadas em areia. Após a germinação as plântulas foram transplantadas para sacos plástico $(18,0 \mathrm{~cm} \times 25,0 \mathrm{~cm} \times 0,15 \mu)$ contendo substrato composto por solo + composto orgânico + casca de arroz carbonizada na proporção de $2: 2: 1$, adicionado $1,5 \mathrm{~kg}$ de termofosfato e $1 \mathrm{~kg}$ de calcário para $1.000 \mathrm{~L}$ do substrato. As plantas foram mantidas em casa de vegetação até que a maioria atingisse $8 \mathrm{~mm}( \pm 2 \mathrm{~mm})$ de diâmetro, quando foram selecionadas 100 plantas para a realização das enxertias.

Foram testados os seguintes tratamentos: a) garfagem lateral; b) garfagem em fenda cheia; c) garfagem em fenda dupla; d) borbulhia em janela aberta e e) borbulhia em janela fechada. $O$ delineamento experimental foi inteiramente casualizado com 5 tratamentos e 4 repetições com 5 plantas por repetição.

As avaliações feitas nas enxertias foram o pegamento e sobrevivência dos enxertos, feitas aos 30 e 60 dias, respectivamente, após a enxertia. As avaliações foram feitas pelo aspecto visual dos enxertos, considerando como pegos e sobreviventes os que apresentavam coloração verde.

As analises estatísticas realizadas foram a verificação da presença de dados discrepantes pelo Teste de Grubbs, verificação da normalidade dos resíduos pelo de teste de Shapiro-Wilk e verificação da homogeneidade de variâncias pelo teste de Bartlett, com os dados não atenderam aos pressupostos da análise de variância foi aplicado o teste não paramétrico de Kruskal-Wallis em todas as variáveis.

\section{RESULTADOS E DISCUSSÃO}

A maior percentagem de estacas vivas e de estacas brotadas e número de brotos foram as do tipo tanchão independente da dose de AIB (50,0\% a 75,3\%) (Tabela 1). A maior sobrevivência dessas estacas é devido a maior quantidade de reservas contidas nas mesmas, motivo pelo qual, favorece também o enraizamento (FACHINELLO et al., 2013).

Houve brotações significantes, entretanto, baixa capacidade de enraizamento. Em estacas apicais de cajá (S. mombin L.) Souza e Lima (2005) também observaram alta taxa de brotação $(50,0 \%$ a $75,0 \%)$ e baixo enraizamento $(8,33 \%$ a $25,0 \%)$ em função das doses $0,500,1.000,1.500$ e $2.000 \mathrm{mg} \mathrm{L}^{-1}$ de AIB, sendo a variabilidade genética dentro da espécie importante para o potencial de enraizamento, que variou de 0,0\% a 30,0\% entre genótipos. 
TABELA 1. Médias de estacas vivas, brotadas e número de brotos de taperebá tratadas com ácido indolbutírico, em Rio Branco, Acre. UFAC, 2017.

\begin{tabular}{|c|c|c|c|c|c|c|}
\hline & \multicolumn{6}{|c|}{ Estacas vivas (\%) } \\
\hline \multirow[t]{2}{*}{$\begin{array}{l}\text { Tipo de } \\
\text { estaca }\end{array}$} & \multicolumn{6}{|c|}{ Concentração AIB (mg L-1) } \\
\hline & 0 & 1.000 & 2.000 & 3.000 & 4.000 & 5.000 \\
\hline Apical & $6,00 \mathrm{Aa}$ & $2,75 \mathrm{Aa}$ & $6,00 \mathrm{Aab}$ & $0,00 \mathrm{Aa}$ & $0,00 \mathrm{Aa}$ & $0,00 \mathrm{Aa}$ \\
\hline Mediana & $11,00 \mathrm{Aa}$ & $0,00 \mathrm{Aa}$ & 2,75 Aab & 1,00 Aab & $0,00 \mathrm{Aa}$ & $0,00 \mathrm{Aa}$ \\
\hline Basal & $16,50 \mathrm{Aab}$ & $2,75 \mathrm{Aa}$ & 5,50 Aab & 2,75 Aab & 2,75 Aa & $0,00 \mathrm{Aa}$ \\
\hline Tanchão & $72,00 \mathrm{Ab}$ & $52,50 \mathrm{Ab}$ & $75,00 \mathrm{Ab}$ & $50,00 \mathrm{Ab}$ & $57,50 \mathrm{Ab}$ & $75,30 \mathrm{Ab}$ \\
\hline \multirow{2}{*}{ Estratificação } & $5,00 \mathrm{Aa}$ & $0,00 \mathrm{Aa}$ & $0,00 \mathrm{Aa}$ & $1,00 \mathrm{Aa}$ & $0,00 \mathrm{Aa}$ & $2,50 \mathrm{Aa}$ \\
\hline & \multicolumn{6}{|c|}{ Brotadas (\%) } \\
\hline Apical & $5,50 \mathrm{Aa}$ & $2,75 \mathrm{Aa}$ & $5,50 \mathrm{Aa}$ & $0,00 \mathrm{Aa}$ & $0,00 \mathrm{Aa}$ & $0,00 \mathrm{Aa}$ \\
\hline Mediana & $11,00 \mathrm{Aa}$ & $0,00 \mathrm{Aa}$ & $2,75 \mathrm{Aa}$ & $8,75 \mathrm{Aa}$ & $0,00 \mathrm{Aa}$ & $0,00 \mathrm{Aa}$ \\
\hline Basal & $14,00 \mathrm{Aab}$ & 2,75 $\mathrm{Aa}$ & $1,00 \mathrm{Aa}$ & $25,00 \mathrm{Aa}$ & $2,75 \mathrm{Aa}$ & $0,00 \mathrm{Aa}$ \\
\hline Tanchão & $72,00 \mathrm{Ab}$ & $52,50 \mathrm{Ab}$ & $62,50 \mathrm{Ab}$ & $50,00 \mathrm{Ab}$ & $57,50 \mathrm{Ab}$ & $75,00 \mathrm{Ab}$ \\
\hline \multirow[t]{2}{*}{ Estratificação } & $5,00 \mathrm{Aa}$ & $0,00 \mathrm{Aa}$ & $0,00 \mathrm{Aa}$ & $10,00 \mathrm{Aa}$ & $0,00 \mathrm{Aa}$ & $2,50 \mathrm{Aa}$ \\
\hline & \multicolumn{6}{|c|}{ Número de brotos por estacas } \\
\hline Apical & $0,00 \mathrm{Aa}$ & $0,00 \mathrm{Aa}$ & $0,03 \mathrm{Aa}$ & $2,75 \mathrm{Aa}$ & $0,00 \mathrm{Aa}$ & $0,00 \mathrm{Aa}$ \\
\hline Mediana & $0,00 \mathrm{Aa}$ & $0,00 \mathrm{Aa}$ & $0,00 \mathrm{Aa}$ & $0,00 \mathrm{Aa}$ & $0,00 \mathrm{Aa}$ & $0,00 \mathrm{Aa}$ \\
\hline Basal & $0,00 \mathrm{Aa}$ & $0,00 \mathrm{Aa}$ & $0,00 \mathrm{Aa}$ & $0,00 \mathrm{Aa}$ & $0,00 \mathrm{Aa}$ & $0,00 \mathrm{Aa}$ \\
\hline Tanchão & $37,30 \mathrm{Ab}$ & $32,50 \mathrm{Ab}$ & $34,50 \mathrm{Ab}$ & $25,00 \mathrm{Ab}$ & $37,50 \mathrm{Ab}$ & $37,50 \mathrm{Ab}$ \\
\hline Estratificação & $0,00 \mathrm{Aa}$ & $0,00 \mathrm{Aa}$ & $0,00 \mathrm{Aa}$ & $0,00 \mathrm{Aa}$ & $0,00 \mathrm{Aa}$ & 2,50 Aa \\
\hline
\end{tabular}

Médias seguidas de letras distintas, minúsculas nas colunas e maiúsculas nas linhas diferem $(p>0,05)$ entre si pelo teste não-paramétrico de Kruskal-Wallis.

Os tipos de estaca e as doses de AIB não interferiram na percentagem de estacas calejadas ( 0 a $12,5 \%$ ), enraizadas e no número de raízes $(0$ a 0,75$)$, exceto para o tipo tanchão que apresentou a maior percentagem de estacas calejadas ( $25 \mathrm{a}$ $37,5 \%$ ) independente da dose de AIB. O enraizamento foi baixo, variando de 0 a $12,5 \%$ (Tabela 2). Este comportamento é comum nas espécies do gênero Spondias (BASTOS et al., 2014), mesmo utilizando auxina exógena, o enraizamento não passa de 2,7\% em S. lutea (HOLANDA et al., 2012); 13,5\% em umbu-cajazeira (Spondias spp) (BASTOS et al., 2014) e 30,5\% em S. tuberosa (RIOS et al., 2012).

A baixa eficiência da aplicação de AIB em estacas de Spondias $s p$. justifica-se pelo grau de lignificação das estacas, concentrações da auxina utilizada, variabilidade genética do genótipo e da espécie e pela liberação de compostos fenólicos que oxidam os tecidos (CUNHA, 2013).

A presença de fenóis, assim como o baixo potencial genético para emissão de raízes podem ser a justificativa para o reduzido enraizamento das estacas de taperebá, sendo importante abordar outros condicionadores de estacas para aumentar o enraizamento, como o estiolamento, nutrição e o estádio fenológico da estaca, para que a quantidade de inibidores diminui e a de cofatores do enraizamento aumentam (FACHINELLO, 2013).

Em umbuzeiro, estacas retiradas em plena atividade vegetativa, enfolhadas, com brotações novas e sem frutos possuem maior capacidade de enraizamento, por apresentarem maiores teores de carboidratos, aminoácidos, proteínas e auxinas em relação à estacas lenhosas e semilenhosas (RIOS et al., 2012). 
TABELA 2. Médias de estacas calejadas, enraizadas e número de raízes de taperebá tratadas com ácido indolbutírico (AIB), em Rio Branco, Acre. UFAC, 2017.

\begin{tabular}{ccccccc}
\hline \multicolumn{7}{c}{ Estacas calejadas $(\%)$} \\
\hline Tipo de estaca & 0 & 1.000 & 2.000 & 3.000 & 4.000 & 5.000 \\
\hline Apical & $0,00 \mathrm{Aa}$ & $0,00 \mathrm{Aa}$ & $0,00 \mathrm{Aa}$ & $2,75 \mathrm{Aa}$ & $0,00 \mathrm{Aa}$ & $0,00 \mathrm{Aa}$ \\
Mediana & $0,00 \mathrm{Aa}$ & $0,00 \mathrm{Aa}$ & $0,00 \mathrm{Aa}$ & $0,00 \mathrm{Aa}$ & $0,00 \mathrm{Aa}$ & $0,00 \mathrm{Aa}$ \\
Basal & $0,00 \mathrm{Aa}$ & $0,00 \mathrm{Aa}$ & $0,00 \mathrm{Aa}$ & $0,00 \mathrm{Aa}$ & $0,00 \mathrm{Aa}$ & $0,00 \mathrm{Aa}$ \\
Tanchão & $34,50 \mathrm{Ab}$ & $37,50 \mathrm{Ab}$ & $33,60 \mathrm{Ab}$ & $25,00 \mathrm{Ab}$ & $37,50 \mathrm{Ab}$ & $37,20 \mathrm{Ab}$ \\
Estratificação & $0,00 \mathrm{Aa}$ & $0,00 \mathrm{Aa}$ & $0,00 \mathrm{Aa}$ & $0,00 \mathrm{Aa}$ & $0,00 \mathrm{Aa}$ & $12,50 \mathrm{Aa}$ \\
\hline \multicolumn{7}{c}{ Enraizadas $(\%)$} \\
\hline Apical & $0,00 \mathrm{Aa}$ & $2,75 \mathrm{Aa}$ & $0,00 \mathrm{Aa}$ & $0,00 \mathrm{Aa}$ & $0,00 \mathrm{Aa}$ & $0,00 \mathrm{Aa}$ \\
Mediana & $0,00 \mathrm{Aa}$ & $0,00 \mathrm{Aa}$ & $2,75 \mathrm{Aa}$ & $5,50 \mathrm{Aa}$ & $0,00 \mathrm{Aa}$ & $0,00 \mathrm{Aa}$ \\
Basal & $0,00 \mathrm{Aa}$ & $2,75 \mathrm{Aa}$ & $0,00 \mathrm{Aa}$ & $0,00 \mathrm{Aa}$ & $0,00 \mathrm{Aa}$ & $0,00 \mathrm{Aa}$ \\
Tanchão & $0,00 \mathrm{Aa}$ & $12,40 \mathrm{Aa}$ & $12,50 \mathrm{Aa}$ & $11,90 \mathrm{Aa}$ & $0,00 \mathrm{Aa}$ & $12,50 \mathrm{Aa}$ \\
Estratificação & $0,00 \mathrm{Aa}$ & $0,00 \mathrm{Aa}$ & $0,00 \mathrm{Aa}$ & $0,00 \mathrm{Aa}$ & $0,00 \mathrm{Aa}$ & $12,50 \mathrm{Aa}$ \\
\hline \multicolumn{7}{c}{$\mathrm{Número} \mathrm{de} \mathrm{raízes}$} \\
\hline Apical & $0,00 \mathrm{Aa}$ & $0,03 \mathrm{Aa}$ & $0,00 \mathrm{Aa}$ & $0,00 \mathrm{Aa}$ & $0,00 \mathrm{Aa}$ & $0,00 \mathrm{Aa}$ \\
Mediana & $0,00 \mathrm{Aa}$ & $0,00 \mathrm{Aa}$ & $0,03 \mathrm{Aa}$ & $0,00 \mathrm{Aa}$ & $0,06 \mathrm{Aa}$ & $0,00 \mathrm{Aa}$ \\
Basal & $0,00 \mathrm{Aa}$ & $0,03 \mathrm{Aa}$ & $0,00 \mathrm{Aa}$ & $0,00 \mathrm{Aa}$ & $0,00 \mathrm{Aa}$ & $0,00 \mathrm{Aa}$ \\
Tanchão & $0,00 \mathrm{Aa}$ & $0,75 \mathrm{Aa}$ & $0,50 \mathrm{Aa}$ & $0,50 \mathrm{Aa}$ & $0,00 \mathrm{Aa}$ & $0,13 \mathrm{Aa}$ \\
Estratificação & $0,00 \mathrm{Aa}$ & $0,00 \mathrm{Aa}$ & $0,00 \mathrm{Aa}$ & $0,00 \mathrm{Aa}$ & $0,00 \mathrm{Aa}$ & $0,10 \mathrm{Aa}$ \\
\hline
\end{tabular}

Médias seguidas de letras distintas, minúsculas nas colunas e maiúsculas nas linhas diferem $(p>0,05)$ entre si pelo teste não-paramétrico de Kruskal-Wallis.

Estacas tanchão de taperebá submetidas as doses $0,2.000$ e $5.000 \mathrm{mg} . \mathrm{L}^{-1}$ de AIB tiveram maior massa seca de brotos. O comprimento da maior raiz e a massa seca de raízes não foram afetados pelo tipo de estaca ou pelas doses de AIB (Tabela 3). Este fenômeno se dá pela maior reserva de carboidrato destas estacas (FACHINELLO, 2013).

TABELA 3. Médias de comprimento da maior raiz, massa seca de raiz e massa seca de brotos de taperebá tratadas com ácido indolbutírico (AIB), em Rio Branco, Acre. UFAC, 2017.

\begin{tabular}{ccccccc}
\hline \multicolumn{7}{c}{ CMR (cm) } \\
\hline Tipo de & 0 & 1.000 & 2.000 & 3.000 & 4.000 & 5.000 \\
\hline Apical & $0,00 \mathrm{Aa}$ & $0,29 \mathrm{Aa}$ & $0,00 \mathrm{Aa}$ & $0,00 \mathrm{Aa}$ & $0,00 \mathrm{Aa}$ & $0,00 \mathrm{Aa}$ \\
Mediana & $0,00 \mathrm{Aa}$ & $0,28 \mathrm{Aa}$ & $0,64 \mathrm{Aa}$ & $0,00 \mathrm{Aa}$ & $0,00 \mathrm{Aa}$ & $0,00 \mathrm{Aa}$ \\
Basal & $0,00 \mathrm{Aa}$ & $0,25 \mathrm{Aa}$ & $0,00 \mathrm{Aa}$ & $0,00 \mathrm{Aa}$ & $0,00 \mathrm{Aa}$ & $0,00 \mathrm{Aa}$ \\
Tanchão & $0,00 \mathrm{Aa}$ & $3,13 \mathrm{Aa}$ & $4,25 \mathrm{Aa}$ & $5,63 \mathrm{Aa}$ & $0,00 \mathrm{Aa}$ & $4,06 \mathrm{Aa}$ \\
Estratificação & $0,00 \mathrm{Aa}$ & $0,00 \mathrm{Aa}$ & $0,00 \mathrm{Aa}$ & $0,00 \mathrm{Aa}$ & $0,00 \mathrm{Aa}$ & $0,00 \mathrm{Aa}$ \\
\hline & & & $\mathrm{MSR}(\mathrm{g})$ & \\
\hline Apical & $0,000 \mathrm{Aa}$ & $0,030 \mathrm{Aa}$ & $0,000 \mathrm{Aa}$ & $0,000 \mathrm{Aa}$ & $0,000 \mathrm{Aa}$ & $0,000 \mathrm{Aa}$ \\
Mediana & $0,000 \mathrm{Aa}$ & $0,000 \mathrm{Aa}$ & $0,003 \mathrm{Aa}$ & $0,003 \mathrm{Aa}$ & $0,000 \mathrm{Aa}$ & $0,000 \mathrm{Aa}$ \\
Basal & $0,000 \mathrm{Aa}$ & $0,003 \mathrm{Aa}$ & $0,000 \mathrm{Aa}$ & $0,005 \mathrm{Aa}$ & $0,000 \mathrm{Aa}$ & $0,000 \mathrm{Aa}$ \\
Tanchão & $0,000 \mathrm{Aa}$ & $1,128 \mathrm{Aa}$ & $0,338 \mathrm{Aa}$ & $0,120 \mathrm{Aa}$ & $0,000 \mathrm{Aa}$ & $2,028 \mathrm{Aa}$ \\
Estratificação & $0,000 \mathrm{Aa}$ & $0,000 \mathrm{Aa}$ & $0,000 \mathrm{Aa}$ & $0,000 \mathrm{Aa}$ & $0,000 \mathrm{Aa}$ & $0,005 \mathrm{Aa}$ \\
\hline \multicolumn{7}{c}{$\mathrm{MSB}(\mathrm{g})$} \\
\hline
\end{tabular}




\begin{tabular}{ccccccc} 
Mediana & $0,001 \mathrm{Aab}$ & $0,000 \mathrm{Aa}$ & $0,038 \mathrm{Aab}$ & $0,048 \mathrm{Aa}$ & $0,000 \mathrm{Aa}$ & $0,000 \mathrm{Aa}$ \\
Basal & $0,023 \mathrm{Aab}$ & $0,055 \mathrm{Aa}$ & $0,005 \mathrm{Aab}$ & $0,005 \mathrm{Aa}$ & $0,003 \mathrm{Aa}$ & $0,000 \mathrm{Aa}$ \\
Tanchão & $0,588 \mathrm{Ab}$ & $5,148 \mathrm{Aa}$ & $5,143 \mathrm{Ab}$ & $0,128 \mathrm{Aa}$ & $0,008 \mathrm{Aa}$ & $4,135 \mathrm{Ab}$ \\
\hline Estratificação & $0,015 \mathrm{Aa}$ & $0,000 \mathrm{Aa}$ & $0,000 \mathrm{Aa}$ & $0,010 \mathrm{Aa}$ & $0,000 \mathrm{Aa}$ & $0,488 \mathrm{Aab}$ \\
\hline
\end{tabular}

Médias seguidas de letras distintas, minúsculas nas colunas e maiúsculas nas linhas diferem $(p>0,05)$ entre si pelo teste não-paramétrico de Kruskal-Wallis.

Não houve diferença entre os tipos de enxertia para as variáveis pegamento e brotação. O pegamento variou entre $16,67 \%$ e $58,33 \%$ e a brotação entre 0,0 e $25,0 \%$ (Tabela 4).

TABELA 4. Médias do pegamento e brotações das enxertias por janela aberta, janela fechada, fenda cheia, fenda dupla e garfagem lateral em taperebá, em Rio Branco, Acre. UFAC, 2017.

\begin{tabular}{lcc}
\hline Enxertia & Pegamento (\%) & Brotação (\%) \\
\hline Janela aberta & $16,67 \mathrm{a}$ & $8,33 \mathrm{a}$ \\
Janela fechada & $50,00 \mathrm{a}$ & $16,67 \mathrm{a}$ \\
Fenda cheia & $41,67 \mathrm{a}$ & $16,67 \mathrm{a}$ \\
Fenda dupla & $33,33 \mathrm{a}$ & $0,00 \mathrm{a}$ \\
Garfagem lateral & $58,33 \mathrm{a}$ & $25,00 \mathrm{a}$ \\
\hline
\end{tabular}

Médias seguidas de mesmas letras, não diferem $(p>0,05)$ entre si pelo teste não-paramétrico de Kruskal-Wallis.

Técnica de enxertia por garfagem tem sido recomendada para diversas espécies do gênero Spondias como o umbu-cajá (Spondias spp.), com até 100\% de pegamento e sobrevivência, dependendo da combinação do enxerto e do portaenxerto e do tipo de enxertia (BASTOS et al., 2014), porém, para as espécies cajámanga e cajá o pegamento do enxerto é menor, 22,0 e $66,7 \%$ respectivamente (LIMA FILHO et al., 2009).

A ausência de brotação quando realizou a enxertia de dupla fenda pode ser decorrente do maior dano aos tecidos e baixa capacidade de cicatrização. Pois em pitangueira esta técnica reduz a brotação dos enxertos comparados a enxertia de fenda dupla, pela lignificação do caule e danos oxidativos que impedem a cicatrização dos cortes (FRANZON et al., 2008).

Um dos fatores que está diretamente relacionado a cicatrização e sobrevivência dos enxertos é o conteúdo de auxina, que é liberada das cadeias vasculares do enxerto e do porta-enxerto e induz a diferenciação de tecidos vasculares, funcionando como substâncias morfogênicas (ALONI et al., 2010).

\section{CONCLUSÕES}

Estacas tanchão tem maior sobrevivência e brotações independente da dose de AIB. As doses de AIB e os tipos de estaca não afetam o enraizamento.

A enxertia por garfagem lateral proporciona maiores taxas de brotação do enxerto, que é baixo (25\%) para esta espécie.

\section{AGRADECIMENTOS}

À CAPES, CNPC e FAPAC pela concessão de bolsa aos autores.

\section{REFERÊNCIAS}


ACRE. Secretaria de Estado de Meio Ambiente. Zoneamento EcológicoEconômico da Acre fase II: recursos naturais: biodiversidade e ambientes do Acre. Rio Branco, AC: Secretaria de Estado de Meio Ambiente, 2010. (Coleção Temática do Zoneamento Ecológico-Econômico, 3).

ALONI, B.; COHEN, R.; KARNI, L.; AKTAS, H.; EDELSTEIN, M. Hormonal signaling in rootstock-scion interactions. Scientia Horticulturae, v. 127, p. 119-126, 2010. Disponível em: <http://www.sciencedirect.com/science/article/pii/S0304423810004115>. doi: 10.1016/j.scienta.2010.09.003.

BASTOS, L. P.; DANTAS, A. C. V. L.; COSTA, M. A. P. C.; BASTOS, M. J. S, M.; ALMEIDA, V. O. Propagação vegetativa de umbu-cajazeira. Enciclopédia Biosfera, Goiânia, v. 10, n. 18, p. 2508-2517, 2014. Disponível em: <www.conhecer.org.br/ enciclop/2014a/AGRARIAS/propagacao\%20vetetativa.pdf>.

CUNHA, P. S. C. F. Enraizamento de estacas de Spondias submetidas a doses de ácido Indolbutírico (AIB) e substratos. Dissertação (Mestrado em Agronomia: Fitotecnia) - Universidade Federal Rural do Semi-Árido, Mossoró, Rio Grande do Norte, 2013.

DUTRA, T. R.; MASSAD, M. D.; SARNENTO, M. F. Q.; OLIVEIRA, J. C. de. Ácido indolbutírico e substratos na alporquia de umbuzeiro. Pesquisa Agropecuária Tropical, Goiânia, v. 42, n. 4, p. 424-429, out./dez. 2012. Disponível em: <www.scielo.br/pdf/pat/v42n4/v42n4a10.pdf>. doi: http://dx.doi.org/10.1590./S198340632012000400010.

FACHINELLO, J. C.; HOFFMANN, A.; NACHTIGAL, J. C. Propagação de Plantas Frutíferas. Brasília, DF: Embrapa Informação Tecnológica, 2013.

FRANZON, R. C.; GONÇALVES, R; da S.; ANTUNES, L. E. D.; RASEIRA, M. do C. B.; TREVISAN, R. Propagação da pitangueira através da enxertia de garfagem. Revista Brasileira de Fruticultura, Jaboticabal, v. 30, n. 2, p. 488-491, jun. 2008. Disponível em: <http://www.scielo.br/scielo.php?script=sci_arttext\&pid=S0100$29452008000200038>$. doi: http://dx.doi.org/10.1590/S0100-29452008000200038.

GÓES, G. B. de; MELO, I. G. C.; MENDONÇA, V.; DANTAS, D. J.; LEITE, G. A. Métodos de enxertia na produção de mudas de tamarindeiro. Revista Ceres, v. 63, n.6, p. 853-859, 2016. Disponível em: <www.scielo.br/scielo.php?script=sci_ abstract\&pid=S0034-737X2016000600853\&lng=pt\&nrm=iso >. doi: http://dx.doi.org/10. 1590/0034-737x201663060015.

HOLANDA, F. S. R.; VIEIRA, T. R. S.; ARAÚJO FILHO, R. N. de; SANTOS, T. de O.; ANDRADE, K. V. S.; CONCEIÇÃO, F. G. da. Propagation through cutting technique of species ocurring in the lower São Francisco river in Sergipe state with different concentrations of indolbutiric acid. Revista Árvore, Viçosa-MG, v.36, n.1, p.75-82, 2012. Disponível em:<http://www.scielo.br/scielo.php?script=sci_arttext\&pid=S010067622012000100009>. doi: http://dx.doi.org/10.1590/S0100-67622012000100009.

LIMA FILHO, J. M. P.; SANTOS, C. A. F. Avaliação fenotípica e fisiológica de espécies de Spondias tendo como porta-enxerto o umbuzeiro (Spondias tuberosa 
Cam.). Revista Caatinga, v. 22, n. 1, p.59-63, jan./mar. 2009. Disponível em:< https://periodicos.ufersa.edu.br/index.php/caatinga/article/view/148/pdf>.

LORENZI, H.; SARTORI, S. F.; BACHER, L. B.; LACERDA, M. T. C. de. Frutas brasileiras e exóticas cultivadas. São Paulo: Instituto Plantarum de estudos da flora. 2006.

RIOS, E. S.; PEREIRA, M. de C.; SANTOS, L. de S.; SOUZA, T. C. de; RIBEIRO, V. G. Concentrações de ácido indolbutírico, comprimento e época de coleta de estacas, na propagação de umbuzeiro. Revista Caatinga, Mossoró, v. 25, n. 1, p. 52-57, jan./mar. 2012. Disponível em: <https://periodicos.ufersa.edu.br/index.php/caatinga/ article/view/2113/pdf>.

SOUZA, F. X. de; COSTA, J. T. A.; COELHO, E. L.; MAIA, A. de H. N. Comportamento vegetativo e reprodutivo de clones de cajazeira cultivados na Chapada do Apodi, Ceará. Revista Ciências Agronômica, v. 43, n. 2, p. 293-300, 2012. Disponível em: <http://ccarevista.ufc.br/seer/index.php/ccarevista/article/view/ 1289/685>. doi:

SOUZA, F. X.; LIMA, R. N. Enraizamento de estacas de diferentes matrizes de cajazeira tratadas com ácido indolbutírico. Revista Ciência Agronômica, v. 36, n. 2, p. 189-194, maio/ago. 2005. Disponível: <http://www.ccarevista.ufc.br/seer/ index.php/ccarevista/article/view/267/262>.

WARSCHEFSKY, E.; CHITWOOD, D. H.; WETTBERG, E. J. B. VON.; KLEIN, L. L.; LONDO, J. P.; FRANK, M. H.; MILLER, A. J. Rootstocks: Diversity, Domestication, and Impacts on Shoot Phenotypes. Trends in Plant Science, v. 21, n.5, p. 418-437, 2016. Disponível em: <https://www.ncbi.nlm.nih.gov/pubmed/26698413>. doi: 10.1016/j.tplants.2015.11.008. 